\title{
La oposición democrática en la génesis revolucionaria (1848-1868)
}

L'opposition démocratique dans la genèse révolutionnaire (1848-1868)

The democratic opposition in the revolutionary genesis (1848-1868)

\section{Manuel Morales Muñoz}

\section{OpenEdition}

\section{Journals}

\section{Edición electrónica}

URL: http://journals.openedition.org/bhce/1497

DOI: $10.4000 /$ bhce. 1497

ISSN: 1968-3723

Editor

Presses Universitaires de Provence

Referencia electrónica

Manuel Morales Muñoz, «La oposición democrática en la génesis revolucionaria (1848-1868) », Bulletin d'Histoire Contemporaine de l'Espagne [En línea], 55 | 2020, Publicado el 01 septiembre 2020, consultado el 28 noviembre 2020. URL : http://journals.openedition.org/bhce/1497 ; DOI : https:// doi.org/10.4000/bhce.1497

Este documento fue generado automáticamente el 28 noviembre 2020

Bulletin d'histoire contemporaine de l'Espagne 


\title{
La oposición democrática en la génesis revolucionaria (1848-1868)
}

\author{
L'opposition démocratique dans la genèse révolutionnaire (1848-1868) \\ The democratic opposition in the revolutionary genesis (1848-1868)
}

\section{Manuel Morales Muñoz}

1 Desde los años cuarenta del siglo xIx, el republicanismo se presentó como la antítesis, y también como la alternativa, de los tradicionales sistemas de representación política, introduciendo sobre la escena pública las reivindicaciones políticas, sociales y culturales que demandaban la pequeña burguesía democrática y las clases populares. Entre otras, el sufragio universal, la libertad de imprenta y la de asociación, o la abolición de los impuestos de consumo, y la de las quintas y las matrículas de mar. En este sentido, la democracia republicana fue una propuesta no sólo de organización política, sino sobre todo de cambio y de reformas sociales y de progreso cultural. Frente al proyecto monárquico, definido por su conservadurismo político-social y el peso de la tradición, y bajo el que encontraba cobijo una oligarquía que controlaba todos los resortes del poder, el republicanismo tenía como señas de identidad más visibles la libertad del individuo, la descentralización, la igualdad política y social, o el impulso educativo y cultural.

2 Un momento clave en la delimitación de aquella propuesta política, se produjo gracias a las iniciativas de un grupo de ciudadanos, que, desde los años cuarenta y cincuenta, divulgaron los principios democráticos en la prensa y en los casinos y tertulias. Se trataba de una elite, compuesta por miembros de la pequeña y mediana burguesía democrática, cuyo compromiso político, social y cultural, los llevó a tomar parte en las jornadas revolucionarias que se sucedieron desde 1848 hasta septiembre de 1868, y que formaron parte de las Juntas de gobierno surgidas de aquellas mismas jornadas, así como de los ayuntamientos constitucionales e incluso del Congreso de los Diputados. 


\section{La cara de la oposición}

3 Dentro de la amplia nómina que engrosó aquellas filas, son bien conocidos los nombres de Sixto Cámara, José Ordax Avecilla, Fernando Garrido, Antonio Ignacio Cervera, José María Orense, Emilio Castelar, Francisco Pi y Margall, y Nicolás María Rivero, a quien Miguel Morayta atribuyó «el empuje (y la) inteligencia» necesarios para formar el partido democrático ${ }^{1}$. Un Rivero que, cuando fue elegido diputado por Écija en 1847, ya formaba parte de los círculos literarios, periodísticos y políticos de la capital, en la que según Antonio Eiras Roel se encontraba defendiendo la doctrina democrática de los derechos naturales del hombre ${ }^{2}$. Estudioso de la filosofía alemana, particularmente de autores hegelianos como Arnold Ruge, Bruno Bauer y Max Stirner ${ }^{3}$, aquel mismo año comenzó a escribir en El Siglo. Periódico progresista constitucional creado para defender el cristianismo, la ciencia, el progreso y la democracia. Al siguiente explicó Filosofía del Derecho en la Academia del Porvenir, sociedad dedicada a la enseñanza de las ciencias, la literatura y las bellas artes, en la que coincidió con progresistas y demócratas como Manuel Cortina, Pascual Madoz, Fernando Corradi, Pedro Felipe Monlau o Juan Martínez Villergas ${ }^{4}$. Y dos años después, su intervención en el Ateneo explicando los principios y tendencias de la Filosofía Moderna, motivaron las quejas de varios socios por los términos en los que se expresó en materias de religión y de política ${ }^{5}$.

4 Por su personalidad y sus trayectorias políticas, otros nombres propios son los de algunos de los miembros del activo núcleo andaluz, como el fourierista Ramón de Cala, impulsor del republicanismo en la comarca de Jerez, por donde fue concejal durante el Bienio progresista, así como presidente de la Junta Revolucionaria de 1868 y alcalde en los primeros momentos del Sexenio democrático de 1868-1874, amén de director del periódico La Igualdad y autor de la obra titulada Los Comuneros de París; el sevillano Antonio Machado Núñez, catedrático de Historia Natural en la Universidad de Sevilla, en la que comenzó a explicar a comienzos de los años sesenta el transformismo darwinista y el positivismo, y de la que fue Rector entre 1868 y 1874. Al tiempo que participó en la "Gloriosa" revolución de septiembre, y fue miembro de la Junta Revolucionaria y alcalde de la ciudad en los primeros momentos; el médico gaditano residente en Sevilla, Federico Rubio Galí, que promovió la creación de la Escuela Libre de Medicina y Cirugía antes de su paso por el Congreso de los Diputados y su nombramiento como embajador en Londres; el médico cordobés Francisco Leiva Muñoz, cuya febril actividad política en la provincia de Córdoba fue rememorada por él mismo, contando en sus memorias cómo su actuación en septiembre de 1868, destrozando un cuadro de Fernando VII y los retratos de Isabel II existentes en la Diputación, estuvo motivado por el recuerdo de la destrucción de las lápidas de la Constitución del doce en 1814 y 1823 y por el de los autos de fe realizados con los cuadros de Espartero y del Duque de la Torre, respectivamente, en 1843 y 18576; el comerciante malagueño Pedro Gómez Gómez, cuya actividad política estuvo marcada desde su juventud por el peso de la memoria familiar, como hijo del médico progresista y director del Hospital de San Juan de Dios, Pedro Gómez Sancho, que fue concejal en 1839, oficial de la Milicia nacional, participante en el levantamiento que acabó con la regencia de Baldomero Espartero en el verano de 1843, diputado a Cortes por el Partido Progresista en las elecciones de septiembre de ese último año, y alcalde de la capital en la legislatura 1843-1844, y quien murió repentinamente en octubre de 1847 , después de pasar meses encarcelado en el castillo 
de Gibralfaro por el gobierno de Ramón María Narváez; los abogados Eduardo Palanca Asensi ${ }^{8}$, José Carvajal-Hué ${ }^{9}$ y Francisco Guillén Robles ${ }^{10}$, quienes participaron desde 1853 en las filas del Círculo Científico y Literario: una sociedad cuyo principal objetivo era «la propaganda de las doctrinas democráticas», y de la que también formó parte el librero krausista Francisco de Moya y Vache, corresponsal y distribuidor de La Discusión en Málaga desde su nacimiento el 2 de marzo de 1856, y quien vendía en exclusiva en la provincia, desde el momento mismo de su publicación en 1860, el folleto político titulado Explicación del programa democrático publicado en La Discusión, escrito «para el pueblo» por Manuel Gómez Marín y prologado por Francisco Piy Margall ${ }^{11}$.

5 Además de los citados, en la oposición a la monarquía de Isabel II militaban igualmente pequeños propietarios, comerciantes, miembros de profesiones liberales, artesanos y trabajadores de oficio, obreros fabriles, jornaleros..., que constituían ya desde los años cuarenta la base social de la democracia. Unos hombres, la mayoría de los cuales estaban excluidos de los estrechos límites del liberalismo censitario, que encontraron en la prensa, en la milicia, en los casinos y en las sociedades secretas de corte carbonario, los cauces necesarios para oponerse al sistema político y social que se estaba construyendo ${ }^{12}$.

De acuerdo con los datos que sobre los encartados en los movimientos revolucionarios de los años cincuenta y sesenta elaboraron los gobernadores de Málaga, con una finalidad claramente represora, de los dos centenares largos de los que conocemos el oficio, el veinticuatro por ciento se dedicaban al campo, incluyendo bajo tal denominación jornaleros, hortelanos, labradores, etc.; el veinte por ciento se repartía entre maestros de escuela, comerciantes, agrimensores, dependientes de comercio, médicos, abogados, militares.....; el dos por ciento eran hacendados o propietarios, y el restante cincuenta y cuatro por ciento pertenecían al mundo de los oficios: particularmente carpinteros, sastres, barberos y albañiles ${ }^{13}$.

7 Y es que, más allá de la vocación intelectual de unos y otros de los citados, o de sus conocimientos filosóficos y científicos, todos ellos aspiraban a introducir cambios que cauterizaran los males sociales, sustituyendo el dolo, por la justicia; el agio, por la buena fe; la explotación, por el asociacionismo; el vicio, por la moralidad; y la miseria, por el bienestar derivado del trabajo, tal y como expresaron los demócratas malagueños como respuesta a las acusaciones que se lanzaron contra ellos como instigadores de la agitación que se vivió en los primeros días de enero de $1856^{14}$.

Gracias a sus iniciativas, las ideas democráticas estaban llegando tanto a los círculos científicos y culturales, como a los casinos recreativos, a las tertulias de los cafés, e incluso a los talleres y a las escuelas nocturnas de adultos, convertidos todos esos espacios en lugares de debate y controversia política, con los que ganar para «la causa del progreso» a las clases populares ${ }^{15}$. De entre los numerosos espacios que sirvieron a tal fin, podemos citar el Café de la Perla, en la madrileña Carrera de San Jerónimo ${ }^{16}$, y el Café Universal, en el que se dio a conocer Nicolás Salmerón ${ }^{17}$; la madrileña sociedad de $E l$ Fomento de las Artes, en el que la propaganda desarrollada durante el reinado isabelino sirvió «pocos años después para producir efervescencia en el período de triunfo de la revolución de Septiembre» ${ }^{18}$, o el reusence Centro de Lectura, en cuya biblioteca se podían encontrar periódicos tan afines a la democracia como La Discusión y El Pueblo. Amén del órgano de prensa de la sociedad, que servía para transmitir a sus socios todo un conjunto de valores y virtudes cívicas entre los que se encontraban la defensa de la 
razón y el progreso, e incluso la consideración del jacobinismo como el motor de la Revolución Francesa ${ }^{19}$.

9 De esta manera, y a despecho de las restricciones legales impuestas, no pocos casinos isabelinos tuvieron una especial relevancia como base de organización y propaganda democrática. Fue en ese mismo contexto, en el que nacieron en Madrid dos sociedades secretas cuyas ramificaciones se extendieron con fuerza por otras provincias. La primera de ellas era la Tertulia del 18 de Junio (1846), que según Fernando Garrido fue una auténtica plataforma para la conspiración en la que se agrupaba toda la juventud revolucionaria: Ordax Avecilla, Abdón Terradas, Corradi, Francisco Javier de Moya..., con el fin de «arrojar formalmente de la palestra a todos los explotadores de la cosa pública» ${ }^{20}$. La segunda era la llamada Los Hijos del Pueblo (c1850), que radicada en Madrid contaba con ramificaciones en Andalucía, y cuyo programa se repartió clandestinamente una década más tarde bajo el título de «Manifiesto político de la Junta Nacional del partido democrático español» ${ }^{21}$.

\section{¿Insurrección vs legalidad?}

10 A este respecto hay que subrayar cómo desde sus mismos orígenes los demócratas se debatieron entre la disyuntiva de actuar dentro de la legalidad o en la clandestinidad. Fluctuando entre su participación en las instituciones y en los levantamientos y asonadas contra la monarquía. Lo que explica que tanto la Tertulia del 18 de Junio como la Academia del Porvenir actuaran, además de como espacios de sociabilidad, como depósitos de armas y como centros de encuadramiento de las bases populares que intervinieron en las tentativas insurreccionales del 26 de marzo y 7 de mayo de $1848^{22}$. Unos levantamientos en los que participaron los sectores más avanzados del progresismo, con Nicolás María Rivero, José María Orense y Ordax Avecilla a la cabeza, y que fue un rotundo fracaso que se saldó con dos centenares de muertos, decenas de presos y desterrados, y la clausura de la Academia del Porvenir ${ }^{23}$.

11 Cuando todavía no se habían apagado los ecos de las insurrecciones del 48, una treintena de progresistas tomaron la iniciativa para fundar el partido democrático, cuyo manifiesto programático se publicó el 6 de abril de $1849^{24}$. Dividido en tres partes, el manifiesto insistía en los principios básicos ya expuestos por José María Orense y Fernando Garrido, y a los que se sumó el derecho a la propiedad privada, la inviolabilidad del domicilio, la libertad de conciencia, de imprenta y de pensamiento, los derechos de reunión y asociación..., la división de poderes, la obligatoriedad y gratuidad de la instrucción primaria, la abolición de los consumos y de las rentas estancadas, o, por último, la supresión de las quintas.... ${ }^{25}$

Semanas más tarde se oficializó el nacimiento del Partido, que contó con el respaldo de más de tres centenares de personas, entre las que se encontraban demócratas históricos como Patricio Olabarría, Wenceslao Ayguals de Izco, Ordax Avecilla, Fernando Garrido, Antonio Ignacio Cervera o Sixto Cámara, que fue el primer secretario de la nueva organización ${ }^{26}$. Y que escasos meses antes había publicado su Espíritu Moderno (1848), obra en la que vinculaba el reconocimiento de los derechos de reunión y asociación y del sufragio universal, con los principios postulados por el incipiente partido ${ }^{27}$.

13 Como otros muchos demócratas, la trayectoria política de Cámara tampoco escapaba a las contradicciones de sus correligionarios, alternando su presencia en las instituciones 
con su participación en las conspiraciones que buscaban acabar con la monarquía. Lo que viene a matizar la tesis que defiende la existencia de dos «orientaciones» contrapuestas en el primer republicanismo: una, que sería de naturaleza insurreccional, y, otra, de acción política institucional y respetuosa con la legalidad ${ }^{28}$. Por encima de sus diferencias sociales, por encima también de sus disparidades ideológicas, que las hubo, lo que les unía a todos ellos era la defensa de aquellos principios que Fernando Garrido calificó como «el dogma de la Democracia»: que no eran otros que el sufragio universal, la soberanía nacional, la libertad de cultos y el derecho de asociación ${ }^{29}$. Unos principios que supusieron una inflexión en el liberalismo individualista hasta entonces imperante.

14 A comienzos de 1854, los periodistas de oposición publicaron un manifiesto denunciando los abusos ministeriales y la deriva autoritaria del Gobierno. Y escasos días después, el 5 de febrero de 1854, mientras que Francisco Pi y Margall y Antonio Ignacio Cervera pudieron ocultarse, Sixto Cámara, Nicolás María Rivero, Ordax Avecilla y otros miembros del comité democrático, fueron detenido por la policía, por su papel en los preparativos de los acontecimientos que tuvieron lugar el verano siguiente ${ }^{30}$.

En el levantamiento de aquel mes de julio de 1854, las clases populares participaron ya bajo la bandera del asociacionismo, que fue difundido por Garrido y otros demócratas socialistas, como instrumento capaz de poner en consonancia el utopismo de Fourier con la acción política de corte republicano ${ }^{31}$. Secundados por aquellas mismas clases, tan pronto como triunfó el alzamiento, algunos grupos se dirigieron a la cárcel del Saladero, liberando a los demócratas encarcelados. Tras lo cual, Rivero, junto con Fernando Corradi y otros conocidos periodistas y antiguos diputados, ocuparon el Ayuntamiento, formándose una comisión encargada de presentar a la reina las exigencias populares. Que no eran otras que las que formaban el programa del partido democrático, es decir, el sufragio universal, la libertad de imprenta, de asociación y de conciencia, la abolición de los consumos y de las rentas estancadas, o la supresión de las quintas ${ }^{32}$.

16 A juicio de Orense, Rivero y otros dirigentes, no cabía más salida que seguir insistiendo en la organización y la difusión de sus ideas, aunque las alternativas y las estrategias eran muy diferentes. En todo caso, las nuevas libertades posibilitaron la proliferación de publicaciones periódicas democráticas, entre las cuales apareció el 2 de marzo de 1856 La Discusión, diario que nació con la intención de difundir las ideas democráticas y fomentar la unión de los progresistas puros y los demócratas.

Dos meses antes de la aparición del periódico, la crisis de trabajo y la mala climatología de aquel invierno, llevaron a centenares de jornaleros y artesanos a concentrarse en Málaga, pidiendo pan y trabajo. Originándose algunos tumultos de los que se culpó, como instigadores, al grupo de demócratas que se reunían en el Círculo Científico y Literario $^{33}$. Unas acusaciones que rechazaron en un manifiesto titulado «El verdadero Partido Democrático», que estaba suscrito por casi un centenar de demócratas, entre los que se encontraban Federico Ferredón ${ }^{34}$, Francisco de Moya, y otros militantes que se habían visto implicados en los sucesos del 26 de julio de 1836, que le costaron la vida a los gobernadores civil y militar de la provincia: conde de Donadío y José de Saint-Just, respectivamente, y en los del verano y otoño de 1854, que provocaron la caída de las primeras autoridades provinciales: Enrique O'Donnell y Miguel Borrego ${ }^{35}$. Entre los mismos se encontraban el corredor de pasas Andrés Silva, que sería elegido concejal en las elecciones de diciembre de 1868; el calderero Miguel Deomarco, padre del futuro 
internacionalista Federico Deomarco, y quien en 1846 se vio envuelto en el asesinato del coronel Trabado; el alfarero Félix Rosso, que había sido concejal en 1843 y 1846; el impresor Antonio Azuaga, que se presentó a la cabeza de los amotinados en las afueras de Málaga cuando los sucesos de Loja del verano de 1861, publicando durante el Sexenio el periódico La Justicia, que actuó como órgano oficioso de la Federación Local de la AIT; el estudiante en leyes Juan Limendoux Sancho, etc. ${ }^{36}$

Individuos, todos ellos, que ayudaron a cimentar la base social sobre la que se conformó la democracia en Málaga, y a quienes las autoridades isabelinas calificaron como «avanzados en ideas y dispuestos a la revolución», «furibundos y acérrimos demócratas», «agitadores y de acción», «peligrosos», extremando la vigilancia sobre los mismos $^{37}$.

el clima político que se encontró el filo-republicano catalán Ceferino Tresserra cuando su visita a Málaga en la primavera de aquel mismo año 1856, durante la que se congratuló del eco que la democracia estaba alcanzando en la ciudad. Y que le movió a exponer un completo programa de «reformas radicales» que afectaban a las relaciones entre el capital y el trabajo, a los derechos y libertades ciudadanas, y al sistema educativo ${ }^{38}$.

Era la misma situación que se vivía en todo el país, lo que llevó a los demócratas a celebrar en junio de ese mismo año 1856, un banquete con el que «unirse, estrechar sus filas y organizarse», y al que asistieron José María Orense, Nicolás María Rivero, Eugenio García Ruiz, Emilio Castelar y Estanislao Figueras, que brindaron por «la unión y concordia del partido democrático», mientras que Fernando Garrido lo hizo por la fraternidad universal ${ }^{39}$. Y ya el 12 de noviembre de aquel año crítico, se levantaron nuevamente en armas contra la monarquía. En esta ocasión, la frustrada insurrección tuvo por escenario la misma Málaga, donde Sixto Cámara, Bernardo García y Romualdo Lafuente, se alzaron al grito de ¡Viva la República!, aprovechando las protestas de la población contra el embarque de tropas para Melilla, en un episodio que se saldó con medio centenar de heridos y seis muertos ${ }^{40}$.

21 Pero la experiencia del Bienio Progresista, con la marginación de los demócratas y el dominio de los unionistas, primero, y la vuelta de los moderados al poder, después, acentuaron las divergencias ideológicas y estratégicas en el seno de la democracia, acabando por cuestionarse la actitud conciliadora de Nicolás María Rivero. Como escribió su biógrafo Cristóbal de Castro, la actividad de Rivero no estuvo exenta de contradicciones. Lo que pretendió explicar como el resultado de una búsqueda de equilibrio entre los principios del pensamiento y la acción, entre la democracia como escuela filosófica y la democracia como partido político, entre el filósofo y el agitador... Aunque al final lo que se acabó imponiendo fue la filosofía y el orden, según aseguró el mismo De Castro.

Así, el año 1856-1857, el mismo en el que tuvo lugar la primera difusión del krausismo en las aulas del Ateneo, gracias al curso que sobre Los principios fundamentales de la moderna filosofía alemana y su influencia en materias religiosas, morales, sociales y políticas corrió a cargo de Manuel Ascensión Berzosa, Rivero dictó otro titulado Origen, progreso y tendencia del espíritu moderno ${ }^{41}$. Todo ello al mismo tiempo que polemizó, junto con Francisco Cárdenas, con los teólogos de la Universidad de Sevilla con motivo de la lección que dedicó a la Ética de Kant ${ }^{42}$. Pero, las actitudes negociadoras, reformistas y parlamentarias de Rivero, su posibilismo frente al régimen isabelino, y su accidentalismo respecto a la forma de gobierno, acabaron chocando con las 
perspectivas insurreccionales de los sectores más radicales. Lo que provocó que sus relaciones con Sixto Cámara se deterioraran. Hasta el punto de que este lo calificó de farsante y aventurero político, por acomodarse a la nueva situación que se creó tras la llegada de la Unión Liberal al poder ${ }^{43}$.

Sin embargo, eso no supuso el cese de las prácticas insurreccionales. Más aún cuando Rivero y los defensores de la vía legalista, con José María Orense, Antonio Ignacio Cervera y Cristino Martos al frente, no podían impedir las arbitrariedades gubernativas. Entre otras, el asesinato el 1 de noviembre de 1858 del abogado y candidato demócrata por el distrito rural de Murviedro (Valencia), Tomás Brú. Y aunque Rivero protestó enérgicamente contra el mismo, fue el gran beneficiado, al salir elegido diputado precisamente por aquel distrito ${ }^{44}$.

24 Fue también Rivero, en unión de Orense, el que inició la apertura de una suscripción en favor de las huérfanas de Brú ${ }^{45}$. Durante los dieciocho meses que duró la colecta, La Discusión publicó centenares de listas que nos permiten dibujar con bastante nitidez la geografía humana del partido a finales de la década. De tal manera, que entre enero de 1859 y julio del año siguiente, se sumaron a la suscripción veintiocho mil seiscientos veinte ciudadanos, particularmente de Cataluña, Valencia y Andalucía, que contribuyeron con más de ciento noventa y siete mil reales. Sólo en Málaga se sumaron a la suscripción ochocientas personas: doscientas de las cuales se identificaron genéricamente como «artesanos», que aportaron entre dos y diez reales ${ }^{46}$.

Se trataba de gente «sencilla» y "de cabeza ligera», cuyas ideas se pervertían, al decir de los respectivos gobernadores de Valencia y Málaga, los moderados Crispín Ximénez de Sandoval y Antonio Guerola, con la lectura de la prensa democrática que los ciegos pregonaban «a voz en grito» en los lugares en los que solían reunirse, y con la de las hojas volanderas y catecismos que circulaban en los mismos medios ${ }^{47}$. Y quienes, al calor de la discusión, podían dar lugar a la «agitación y al motín», no ocultando «sus principios hostiles al Gobierno» ${ }^{48}$.

De hecho, durante los dos años de gobierno moderado, en los que los demócratas volvieron a la clandestinidad, se organizaron nuevamente en sociedad secreta carbonaria, cuyo programa se repartió clandestinamente el $1^{\circ}$ de febrero de 1858 bajo el título de Manifiesto político de la Junta Nacional del partido democrático español ${ }^{49}$. Detrás de aquella iniciativa se encontraban ilustres exiliados como Sixto Cámara, que durante el invierno de 1857-1858 permaneció en Lisboa preparándose para un levantamiento en Andalucía, donde según parece contaban con ochenta mil afiliados; Ceferino Tressera, que en diciembre regresó de su exilio italiano, y Fernando Garrido, quien durante su exilio en Londres estableció contacto con las principales figuras de la Internacional Democrática, como Giuseppe Mazzini o Alexandre-Auguste Ledru-Rollin. Fueron ellos tres los que reactivaron y extendieron la red clandestina en contra de la opinión de Nicolás Rivero ${ }^{50}$.

\section{Las intentonas insurreccionales de 1859, 1861 y 1866}

En aquel contexto, el primero en tomar las armas una vez más fue Sixto Cámara, quien en julio de 1859 se puso al frente de una nueva intentona insurreccional que le terminó costando la vida el día 9 de ese mismo mes. Su muerte sirvió a José María Orense, secundado por Rivero, para rechazar los movimientos insurreccionales y el carácter amenazador de las propuestas socialistas ${ }^{51}$. Por contra, Fernando Garrido y Ceferino 
Tresserra alegaban que era necesario perseverar en aquella línea, tomando como modelo a Giuseppe Garibaldi, cuya figura ocupó un papel central en la retórica, el estilo, e incluso la identidad de los dirigentes demócratas vinculados al levantamiento de Loja de $1861^{52}$. Para Garrido, el verdadero demócrata era al mismo tiempo socialista, porque fundaba «sus esperanzas para la regeneración de la sociedad en la libre práctica del derecho de asociación $»^{53}$.

Para evitar la ruptura, el 12 de noviembre de 1860 se publicó la llamada Declaración de los treinta, en la que se consideraba como demócrata a todo aquel que, con independencia de sus opiniones «en filosofía y en cuestiones económicas y sociales», defendiera como principios fundamentales las libertades individuales y el sufragio universal. Una declaración que firmaron, entre otros, Francisco Pi y Margall, Romualdo Lafuente, Bernardo García, Ángel Cenagorta, Eugenio García Ruiz, Roque Barcia, e incluso José María Orense. Pero no así Rivero ${ }^{54}$.

Cuando todavía no se habían apagado los ecos de la polémica, el 28 de junio de 1861 tuvo lugar el llamado levantamiento de Loja, que marcó abiertamente la división dentro del partido entre individualistas y socialistas. O lo que es lo mismo, entre Nicolás Rivero, José María Orense, Emilio Castelar y Cristino Martos, por un lado, y Fernando Garrido, Sixto Cámara y Francisco Pi y Margall, por otro.

Por un opúsculo escrito años después por el cabecilla de las revueltas, el albéitar Rafael Pérez del Álamo, sabemos cómo el origen del levantamiento hay que buscarlo en la Sociedad secreta democrática socialista carbonaria republicana garibaldina, que tenía por bandera el programa político y económico que ostentaba el periódico demócrata $L a$ Discusión $^{55}$. De acuerdo con las memorias del ya citado gobernador Guerola, la Garibaldina basaba su propaganda en el ofrecimiento de socorro material y moral a los trabajadores y en la difusión «entre las clases pobres (de) ideas absurdas de la excelencia de una democracia exagerada, fundada en que cuando sea Gobierno repartirá los bienes de los ricos y no habrá quintas, ni contribuciones, ni ejército, ni pobres, pero que en cambio habrá libertad para todos ${ }^{56}$.

31 Gracias a ello, la sociedad se extendió por las provincias de Granada, Jaén y Málaga, secundando la insurrección, en esta última, más de cuatro mil personas procedentes de la capital, de los partidos rurales y de la comarca de Antequera. El número de implicados, la implantación de la sociedad en su doble vertiente rural y urbana, y la personalidad de algunos de los encartados, muestra bien a las claras la amplitud de su base social, lo que vendría a matizar la afirmación de Gregorio de la Fuente, sobre la «baja capacidad» de movilización popular de los demócratas, con anterioridad a la toma del poder en septiembre de $1868^{57}$.

32 Frustrado el levantamiento, la represión que le siguió y que desarticuló totalmente la infraestructura de la organización fue ejemplar, como prueban las condenas impuestas. Se dictaron una treintena de condenas a muerte: de las que se ejecutaron seis; treinta y cuatro cadenas perpetuas, y algo más de cuatrocientas penas de cárcel que oscilaron entre los ocho y los veinte años, en los presidios de Canarias, Baleares y Santoña. Con tales penas se cumplían los deseos del propio gobernador Guerola, quien argumentaba que la utilización de «medios de represión enérgicos», tenían la virtud de escarmentar a los levantiscos y producir «efecto muy duradero y enseñanza muy saludable» ${ }^{58}$.

Sin embargo, el 3 de septiembre de 1862, poco más de trece meses después del levantamiento, las autoridades aprobaron el indulto para los encartados en el mismo, si 
bien los que fueron condenados en rebeldía debían solicitarlo personalmente. Es lo que hizo el propio Pérez del Álamo, que se presentó ante el gobernador civil de Sevilla para solicitar su indulto acompañado por Rivero, que fue quien encabezó en las Cortes la petición de la amnistía ${ }^{59}$. También en esta ocasión La Discusión abrió una suscripción con la que socorrer a los presos que estaban saliendo de las cárceles: la mayoría de ellos trabajadores empobrecidos y enfermos que carecían de recursos para volver a sus hogares. Tal fue el caso de Miguel García García, vecino de Alfarnate (Málaga), que murió en Alicante durante el tránsito desde las Baleares hasta su pueblo, y cuyo sepelio costearon los demócratas alicantinos dando pruebas de su «amor a las creencias democráticas»; según destacaban en La Discusión ${ }^{60}$.

Tras la caída del gobierno O’Donnell en febrero de 1863, el marqués de Miraflores convocó nuevas elecciones a Cortes para el 11 de octubre. Pero la ambigüedad ministerial llevó a progresistas y demócratas a retraerse de cara a aquellos comicios. Paralelamente, al tiempo que Rivero publicó un manifiesto en favor de la abstención, la fracción socialista del partido reanudó su actividad conspiratoria, preparándose un levantamiento en Andalucía para abril. Pero la vigilancia de las autoridades, y la falta de recursos, hicieron fracasar la asonada, que se cerró con la detención de los principales alborotadores. Entre ellos, Romualdo Lafuente, que fue condenado a nueve meses de prisión ${ }^{61}$.

La división entre los demócratas a propósito del sentido socialista de unos y otros se acentuó después de las críticas de Emilio Castelar a dicha doctrina desde las páginas de La Democracia, y tras sustituir Pi y Margall a Rivero al frente de La Discusión, en abril de 1864. Unas tensiones que se superpusieron a la lucha por el liderazgo del partido y por las mayores expectativas de acceder al poder ${ }^{62}$. Así, el 16 de julio de 1865, Nicolás María Rivero, Estanislao Figueras, Eduardo Chao, Nicolás Salmerón y otros miembros del comité democrático, renunciaron a su presencia en el mismo, disconformes con la marcha del partido y con la política de Castelar, partidario de un entendimiento con los progresistas. Para Eiras Roel, la razón por la que Rivero tomó esa decisión no era otra que cuestionar la jefatura que, según pensaba Rivero, le había «arrebatado» Castelar ${ }^{63}$.

Pero esas diferencias no impidieron que en las postrimerías del reinado unos y otros conspiraran contra la monarquía. Siguiendo la línea de actuación emprendida por Sixto Cámara en los años 1857 y 1859, en la primavera de 1866 se planeó llevar a cabo una conspiración militar que fue secundada por las manifestaciones populares organizadas desde los clubes democráticos. Tal fue el sesgo que mostró el levantamiento de los sargentos del cuartel de San Gil el 22 de junio de 1866, que acabó con la intervención del propio ejército al mando del general Zavala, y que costó la vida a unos doscientos hombres, casi seiscientos heridos y un millar de prisioneros. Juzgados por tribunales militares, fueron condenados a muerte casi dos centenares de ellos: de los cuales se fusilaron a sesenta y seis, entre el 25 de junio y el 7 de julio. También fueron condenados a muerte los dirigentes civiles: la mayoría de los cuales huyó al exilio. A París se trasladaron Pi y Margall, Eduardo Chao, García López y Emilio Castelar, quienes solían reunirse en el parisino café de Madrid o en la casa de algunos de ellos, particularmente en la de Castelar. Fue en una cena celebrada allí, en la que formaron un Centro democrático que debió coordinarse con el Círculo democrático impulsado por Orense en Burdeos, con la Junta revolucionaria organizada por Roque Barcia en Oporto, y con la Junta revolucionaria de Madrid, de la que eran miembros Figueras y Rivero, que la presidió ${ }^{64}$. 


\section{Epílogo: el tiempo de la «Gloriosa»}

En la capital, Rivero pudo continuar ejerciendo la abogacía, formando parte de la Directiva del Colegio de Abogados de Madrid, en diciembre de 1866. Lo que no le evitó seguir siendo sospechoso y ser encausado ocho meses antes en el proceso abierto contra los redactores y cómplices del periódico clandestino La hoguera y el puñal ${ }^{65}$. Más aún, cuando estaba participando de manera encubierta en los preparativos de la Revolución de septiembre de 1868, tras cuyo triunfo ocupó la presidencia de la Junta provisional revolucionaria que se formó el día 29 en la casa consistorial de Madrid. Y que, fusionada con la dirigida por Juan Antonio Escalante, dio paso a una Junta superior revolucionaria cuyo protagonismo en la legitimación del Gobierno provisional y en el triunfo del programa democrático, le permitió a Rivero ocupar la alcaldía de la capital.

A partir de aquel momento, y tras la aceptación de la Monarquía por parte de una fracción de la democracia, el Partido se dividió. Más aún, cuando el ejército aplastó la resistencia de los Voluntarios de la Libertad a desarmarse, en ciudades como Cádiz, Jerez o Málaga, condenando al fracaso las esperanzas que los demócratas filorepublicanos, habían depositados en la "Gloriosa". Como acertadamente viera Élisée Reclús, ni el ejército ni el Gobierno provisional, cuyos más caracterizados miembros eran los generales Juan Prim y Francisco Serrano, y el almirante Juan Bautista Topete, «jamás tuvieron la intención de dejar franco el paso al pueblo soberano, (y mucho menos) que la República pudiera salir de su pronunciamiento de Septiembre» ${ }^{66}$.

\section{NOTAS}

1. Miguel morayta, Las constituyentes de la República española, Pamplona, Urgoiti Editores, 2012, p. 39.

2. Antonio EIRAS ROEL, El Partido Demócrata Español (1849-1868), Madrid, Ediciones Rialp, 1961, p. 129.

3. Manuel OVILO Y OTERO, «La literatura y la prensa en España», en Escenas Contemporáneas. Revista General Histórica, Biográfica, Necrológica, Científica y Literaria. Y memoria de los sucesos ocurridos en las provincias, pueblos y ayuntamientos de España desde Julio de 1856, por.., Madrid, Imprenta de Higinio Reneses, Enero 1857, p. 121-136 (particularmente la p. 127)

4. El Eco del Comercio, 18 de enero de 1848.

5. Rafael María de LABRA, «El Ateneo de Madrid VI», en Revista Contemporánea, 30 de mayo de 1878, número 60, tomo XV, volumen II, p. 175-190 (www.filosofia.org).

6. F. LEIVA Y MUÑOZ, La batalla de Alcolea o memorias íntimas, políticas y militares de la revolución española de 1868, Córdoba, Imprenta, librería y tipografía del Diario, 1879, 3 tomos. Sus actividades en Juan DÍAZ DEL MORAL, Historia de las agitaciones campesinas andaluzas-Córdoba (Antecedentes para una reforma agraria), Madrid, Revista de Derecho

Bulletin d'Histoire Contemporaine de l'Espagne, 55 | 2020 
Privado, 1929, p. 83 (cit. por la ed. de 1973), y Gregorio DE LA FUENTE MONGE, Los revolucionarios de 1868. Elites y poder en la España liberal, Madrid, Marcial Pons, 2000, p. 97. 7. Pedro Gómez chaIX, D. Pedro Gómez Sancho. Estudio biográfico, Madrid, Imprenta de los Hijos de M. G. Hernández, 1898.

8. Impulsor de la sociedad cultural Lope de Vega, miembro del Partido Democrático y años después del Partido Republicano, por el que fue elegido diputado en 1869, 1871, 1872 y 1873. Ministro de Ultramar durante la Primera República, miembro de la Logia Menova, de Vélez-Málaga, y accionista de la Institución Libre de Enseñanza cuando su fundación en 1877, su biografía, en Diego Caro Cancela (Dir.), Diccionario de Parlamentarios de Andalucía, 1810-1869, Volumen H-Z, Sevilla, Centro de Estudios Andaluces, 2010, p. 319-322.

9. Colaborador de la revista krausista La Razón, diputado en las elecciones de 1872 , ocupó las carteras de Hacienda y de Estado en la primera experiencia republicana de 1873. Unos breves apuntes biográficos sobre el mismo, en Francisco GUILLÉn ROBLES, Historia de Málaga y su provincia, Málaga, Imprenta de Rubio y Cano, 1874, p. 670. Para su colaboración en La Razón, véanse Tomo II, Madrid, Imprenta de M. Galiano, 1861, p. 414-423, y Tomo III, 1861, p. 24-36 y p. 311-321.

10. Abogado e historiador, fue diputado a Cortes en 1872, autor de una Historia de Málaga y su provincia (1874), y de Málaga Musulmana (1880), y, ya en los años ochenta, bibliotecario de la Biblioteca Nacional, en Cristóbal cuevas (Dir. y Ed.), Diccionario de escritores de Málaga y su provincia, Madrid, Editorial Castalia, 2002, p. 387-391.

11. La Discusión, 29 de julio de 1860, y Manuel MORALES MUÑOZ, El librero Francisco de Moya. Un krausista de provincias, Cádiz, Editorial UCA-UMA Editorial, 2018.

12. Manuel MORALES MUÑOZ, «La primera en el peligro de la libertad», en Manuel Morales Muñoz (edit.), La primera en el peligro de la libertad, Málaga, poder político y poder económico (1808-1868), Málaga, Ediciones del Genal, 2012, p. 21-101.

13. Manuel MORALES MUÑOZ, Málaga, la memoria perdida: los primeros militantes obreros, Málaga, Servicio de Publicaciones de la Diputación Provincial, 1989.

14. Los disturbios y las acusaciones contra los demócratas, en El Avisador Malagueño, 10 de enero de 1856. Su respuesta, en El Avisador Malagueño, 19 de enero de 1856.

15. Fernando GARRIDO, Historia del reinado del último Borbón de España. De los crímenes, apostasías, opresión, corrupción, inmoralidad, despilfarros, hipocresía, crueldad y fanatismo de los gobiernos que han regido España durante el reinado de Isabel de Borbón, Barcelona, Salvador Manero Editor, 1868-1869, Volumen III, p. 171.

16. Juan José GIL CREMADES, Krausistas y liberales, Madrid, Seminarios y Ediciones, 1975, p. 59-60.

17. Fernando MARTÍNEZ, «Nicolás Salmerón y Alonso. Entre la revolución y la política», en Javier MORENO LUZÓN (Ed.), Progresistas. Biografías de reformistas españoles (1808-1939), Madrid, Taurus, 2005, p. 129-160 (particularmente, p. 137).

18. Anselmo LORENZO, El proletariado militante. Memorias de un Internacional. Primer período de la Asociación Internacional de los Trabajadores en España, Barcelona, Antonio López, 1901, p. 34.

19. Pere Anguera, El Centre de Lectura de Reus. Una institució ciutadana, Barcelona, Edicions 62, 1977, p. 9-37.

20. Fernando GARRIDO, Historia del reinado del último Borbón de España. De los crímenes, apostasías, opresión, corrupción, inmoralidad, despilfarros, hipocresía, crueldad y fanatismo de 
los gobiernos que han regido España durante el reinado de Isabel de Borbón, Barcelona, Salvador Manero Editor, 1868-1869, volumen II, p. 938.

21. Demetrio CASTRO ALFIN, «Unidos en la adversidad, unidos en la discordia: el Partido Demócrata, 1849-1868», en Nigel Townson (ed.), El republicanismo en España (1830-1977), Madrid, Alianza Editorial, 1994, p. 65-66.

22. Antonio EIRAS ROEL, El Partido Demócrata Español (1849-1868), Madrid, Ediciones Rialp, 1961, p. 132-150.

23. Fernando GARRIDO, La España contemporánea. Sus progresos morales y materiales en el siglo XIX, Prólogo de Florencia Peyrou y Manuel Pérez Ledesma, Pamplona, Urgoiti Editores, 2009, p. XIX-XX.

24. Miguel moRAYTA, Las constituyentes de la República española, Prólogo de Jorge Vilches, Pamplona, Urgoiti Editores, 2012, p. 39.

25. Antonio eIRAS RoEL, El Partido Demócrata español (1849-1868), Madrid, Ediciones Rialp, 1961, p. 162-165 y 200-201.

26. Fernando GARRIDO, La España contemporánea. Sus progresos morales y materiales en el siglo XIX, Prólogo de Florencia Peyrou y Manuel Pérez Ledesma. Pamplona, Urgoiti Editores, 2009, p. XXI.

27. Sixto SÁENZ DE LA CÁMARA, Espíritu Moderno, o sea carácter del movimiento contemporáneo. Sucedido de algunas medidas de gobierno aplicables a la situación de España, Madrid, s.n., 1848.

28. Demetrio CASTRO ALFín, «Orígenes y primeras etapas del republicanismo en España», en Niguel Townson (ed.), El republicanismo en España (1830-1977), Madrid, Alianza Editorial, 1994, p. 42.

29. Fernando GARRIDO, Historia del reinado del último Borbón de España. De los crímenes, apostasías, opresión, corrupción, inmoralidad, despilfarros, hipocresía, crueldad y fanatismo de los gobiernos que han regido España durante el reinado de Isabel de Borbón, Barcelona, Salvador Manero Editor, 1868-1869, volumen III, p. 852.

30. Miguel MORAYTA, Las constituyentes de la República española. Prólogo de Jorge Vilches. Pamplona, Urgoiti Editores, 2012, p. 39.

31. Juan José GIL CREMADES, Krausistas y liberales, Madrid, Seminarios y Ediciones, 1975, p. 63.

32. Antonio eIRAS RoEL, El Partido Demócrata Español (1849-1868), Madrid, Ediciones Rialp, 1961, p. 200-201.

33. El Avisador Malagueño, 10 de enero de 1856.

34. Oficial del Juzgado de La Merced, además de su actividad política, Ferredón es autor del folleto Asociación y derecho al trabajo, cuya publicación en 1856 le costó ser condenado a prisión en un consejo de guerra acusado de conspiración, así como de sendas biografías críticas sobre Robespierre y Marat. Su encarcelamiento en La Iberia, 5 de septiembre de 1856. Las biografías fueron publicadas, respectivamente, en La Tertulia. Suplemento al Nacional, de literatura y de artes, 28 de diciembre de 1851, p. 5, y en la Revista Semanal Pintoresca del Avisador Malagueño. Colección de lecturas de literatura, historia, ciencia, viajes, novelas y anécdotas, Málaga, Imprenta del Avisador Malagueño, Año 1853, número 22, p. 175-176. Una breve semblanza del mismo, en Cristóbal cuEvas (dirección y edición), Diccionario de escritores de Málaga y su provincia, Madrid, Editorial Castalia, 2002, p. 287-288.

35. Los sucesos de uno y otro año, en Colección de las causas más célebres, los mejores modelos de alegatos, acusaciones fiscales, interrogatorios y defensas en lo civil y criminal del foro español, por una Sociedad literaria de amigos colaboradores. Tomo VI, Barcelona, Imprenta de Ignacio Estivill, 1845, p. 209-313; El Avisador Malagueño, 12 y 24 de noviembre de 1854, 
y 29 y 30 de diciembre de 1854; José JIMÉNEZ GUERRERO, Los sucesos de diciembre de 1854 en Málaga, Málaga, Servicio de Publicaciones de la Diputación Provincial, 1994.

36. El texto, y los firmantes del mismo, en El Avisador Malagueño, 19 de enero de 1856.

37. «Lista de los liberales que los gobiernos moderados tenían en un libro reservado, clasificados por los exgobernadores Guerola y Alonso, para perseguirles», en Bandos y proclamas revolucionarios de 1868 a 1874. Archivo Municipal de Málaga (AMMa); Manuel MORALES MUÑOz, Málaga, la memoria perdida. Los primeros militantes obreros, Málaga, Servicio de Publicaciones de la Diputación Provincial, 1989.

38. Antonio EIRAS ROEL, El partido demócrata español (1849-1868), Madrid, Ediciones Rialp, 1961, p. 224-225.

39. Fernando GARRIDO, La España contemporánea. Sus progresos morales y materiales en el siglo XIX. Prólogo de Florencia Peyrou y Manuel Pérez Ledesma. Pamplona, Urgoiti Editores, 2009, p. XXXII.

40. El Avisador Malagueño, 13, 14, 15, 16 y 18 de noviembre de 1856; La Discusión, 18 y 19 de noviembre de 1856, y Clara E. LIDA, Anarquismo y revolución en la España del XIX, Madrid, Siglo XXI de editores, 1972, p. 82-83.

41. Jun José GIL CREMADES, Krausistas y liberales, Madrid, Seminarios y Ediciones, 1975, p. 81-82.

42. José Luis VILlaCAÑAS (ed.), Kant en España: el neokantismo en el siglo XIX, Madrid, Editorial Verbum, 2006, p. 24.

43. Fernando GARRIDO, Historia del reinado del último Borbón de España. De los crímenes, apostasías, opresión, corrupción, inmoralidad, despilfarros, hipocresía, crueldad y fanatismo de los gobiernos que han regido España durante el reinado de Isabel de Borbón, Barcelona, Salvador Manero Editor, 1868-1869, volumen III, p. 294.

44. Francesc A. MARTíNEZ GALLEGO, «Democracia y República en la España isabelina. El caso de Ayguals de Izco», en Manuel CHUST (ed.), Federalismo y cuestión federal en España. Castellón, Universitat Jaume I, 2004, p. 45-90 (particularmente, p. 85-86).

45. Biografías de los Diputados a Cortes de la Asamblea Constituyente de 1869, con los retratos de los mismos... Por una Sociedad de Literatos, Madrid, Imprenta a cargo de Tomás Alonso, Tomo I, p. 7-23.

46. Guy THOMSON, El nacimiento de la política moderna en España. Democracia, asociación y revolución, 1854-75, Granada, Editorial Comares, 2014, p. 105-106.

47. La utilización de los catecismos, en Antonio GUEROLA, Memoria de mi administración en la provincia de Málaga como Gobernador de ella desde 6 de diciembre de 1857 hasta el 15 de febrero de 1863. Sevilla, Fundación Sevillana de Electricidad, 1995, Tomo III, p. 1069. Su papel como medio de propaganda doctrinal, en Manuel MORALES MUÑOZ, El republicanismo malagueño en el siglo XIX. Propaganda doctrinal, prácticas políticas y formas de sociabilidad, Málaga, Asukaría Mediterránea, 1999, p. 26-41. La referencia a Valencia, en Francesc A. MARTÍNEZ GALLEGO, «Democracia y República en la España isabelina. El caso de Ayguals de Izco», en Manuel CHUST (ed.), Federalismo y cuestión federal en España, Castellón, Universitat Jaume I, 2004, p. 85-86.

48. Antonio GUEROLA, Memoria de mi administración en la provincia de Málaga como Gobernador de ella desde 6 de diciembre de 1857 hasta el 15 de febrero de 1863, Sevilla, Fundación Sevillana de Electricidad, 1995, Tomo III, p. 1065-1074, y Tomo IV, p. 1371. 
49. Antonio EIRAS ROEL, El Partido Demócrata Español (1849-1868), Madrid, Ediciones Rialp, 1961, p. 237-241.

50. Clara E. LIDA, Anarquismo y revolución en la España del XIX, Madrid, Siglo XXI de editores, 1972, p. 80-81 y 123-128, y Jordi MALUQUER DE MOTES, «Los orígenes del movimiento obrero español», en La Era isabelina y el Sexenio democrático, 1834-1874, Madrid, Espasa-Calpe, 1981 (Historia de España Menéndez Pidal, vol. XXXIX), p. 795. 51. La Discusión, 9 de octubre y 8, 9, 10 y 25 de noviembre de 1860.

52. Guy тномSon, El nacimiento de la política moderna en España. Democracia, asociación y revolución, 1854-75, Granada, Editorial Comares, 2014, p. 159.

53. La Discusión, 7 y 27 de noviembre de 1860.

54. La Discusión, 16 de noviembre de 1860.

55. Rafael PÉREZ DEL ÁLAMO, Apuntes sobre dos revoluciones andaluzas, Sevilla, Imp. y Litografía, 1872.

56. Antonio GUEROLA, Memoria de mi administración en la provincia de Málaga como Gobernador de ella desde 6 de diciembre de 1857 hasta el 15 de febrero de 1863, Sevilla, Fundación Sevillana de Electricidad, 1995, Tomo III, p. 1085.

57. Gregorio DE LA FUENTE, «Actores y causas de la revolución de 1868», en Rafael SERRANO GARCíA (Dir.), España, 1868-1874. Nuevos enfoques sobre el Sexenio democrático, Valladolid, Junta de Castilla y León, 2002, p. 55.

58. Antonio GUEROLA, Memoria de mi administración en la provincia de Málaga como Gobernador de ella desde 6 de diciembre de 1857 hasta el 15 de febrero de 1863, Sevilla, Fundación Sevillana de Electricidad, 1995, Tomo III, p. 1091-1119 (Sus deseos, en p. 1101).

59. Guy Thomson, El nacimiento de la política moderna en España. Democracia, asociación y revolución, 1854-75, Granada, Editorial Comares, 2014, p. 285.

60. La Discusión, 24 de octubre de 1862. Véanse igualmente los números de fecha 6,16 y 18 de septiembre, y 21 de octubre de 1862.

61. Guy thomson, El nacimiento de la política moderna en España. Democracia, asociación y revolución, 1854-75, Granada, Editorial Comares, 2014, p. 296-300.

62. C.A.M. HENNESSY, La República Federal en España. Pi y Margall y el movimiento republicano federal 1868-74, Madrid, Aguilar, 1967, p. 22-35.

63. Antonio EIRAS ROEL, El Partido Demócrata Español (1849-1868), Madrid, Ediciones Rialp, 1961, p. 308-310.

64. Fernando GARRIDO, La España contemporánea. Sus progresos morales y materiales en el siglo XIX. Prólogo de Florencia Peyrou y Manuel Pérez Ledesma, Pamplona, Urgoiti Editores, 2009, p. XXXIX-XL.

65. Vicente DE LA FUENTE, Historia de las sociedades secretas, antiguas y modernas en España, y especialmente de la Franc-Masonería, Lugo, Imprenta de Soto Freire, editor, 1871, Tomo II, p. 362. 66. Élisée RECLÚS, «Impresiones durante un viaje por España en días de revolución», en La Revista Blanca, 15 de octubre de 1932, p. 484. 


\section{RESÚMENES}

Desde los años cuarenta del siglo xix, el republicanismo se presentó como la alternativa a los tradicionales sistemas de representación política, introduciendo sobre la escena pública las reivindicaciones políticas, sociales y culturales que demandaban la pequeña burguesía democrática y las clases populares. Determinar quiénes fueron algunos de los actores políticos que se encontraban detrás de aquellas propuestas, y exponer los procedimientos a los que recurrieron en su oposición a la monarquía de Isabel II, hasta su caída tras la «Gloriosa» Revolución de septiembre de 1868, es el objetivo de las páginas que siguen.

À partir des années quarante du XIXe siècle, le républicanisme a été présenté comme une alternative aux systèmes traditionnels de représentation politique, introduisant sur la scène publique les revendications politiques, sociales et culturelles de la petite bourgeoisie démocratique et des classes populaires. Déterminer qui étaient certains des acteurs politiques à l'origine de ces propositions et exposer les procédures auxquelles ils ont eu recours pour s'opposer à la monarchie d'Élisabeth II, jusqu'à sa chute après la «Glorieuse» révolution de septembre 1868, est la objectif des pages suivantes.

From the forties of the nineteenth century, republicanism was presented as the alternative to the traditional systems of political representation, introduced on the public scene demands political, social and cultural demanded by the democratic petty bourgeoisie and the popular classes. Determine who were some of the political actors who were behind those proposals, and expose the procedures to which they resorted in their opposition to the monarchy of Elizabeth II, until his fall after the «Glorious» Revolution of September 1868, is the objective of the following pages.

\section{ÍNDICE}

Mots-clés: Démocrates, Républicains, suffrage universel, Révolution de 1868.

Palabras claves: Demócratas, Republicanos, Sufragio universal, Revolución de 1868.

Keywords: Democrats, Republicans, Universal Suffrage, Revolution of 1868.

\section{AUTOR}

\section{MANUEL MORALES MUÑOZ}

Universidad de Málaga 